\title{
CANNIBALISTIC CATERPILLARS (UTETHEISA ORNATRIX; LEPIDOPTERA : ARCTIIDAE) FAIL TO DIFFERENTIATE BETWEEN EGGS ON THE BASIS OF KINSHIP1
}

\author{
By JAMES F. HARE ${ }^{2}$ AND THOMAS EISNER ${ }^{3}$
}

\begin{abstract}
Utetheisa ornatrix larvae, in exercising egg cannibalism, do not discriminate between kin and nonkin. Under natural conditions this may not be a handicap, partly because the larvae hatch largely in synchrony and do not immediately upon emergence engage in cannibalism.
\end{abstract}

\section{INTRODUCTION}

Survival, in the arctiid moth Utetheisa ornatrix, is closely linked to this insect's utilization of pyrrolizidine alkaloids (PAs) (Eisner and Meinwald, 1995). The caterpillar sequesters the chemicals obtained from its food plants (legumes of the genus Crotalaria), retains them through metamorphosis, and as an adult bestows them upon its eggs. All stages of development are protected as a result-adults against orb-weaving spiders (Eisner and Meinwald, 1987), larvae against lycosid spiders (Eisner and Eisner, 1991), and eggs against coccinellid beetles (Dussourd, Ubik, Harvis, Resch, Meinwald, and Eisner, 1988) and ants (Hare and Eisner, 1993). Interestingly, PAs do not protect $U$. ornatrix against conspecific attack. The larvae are cannibalistic, and may feed on both pupae and eggs (Bogner and Eisner, 1991; 1992). However, the relative contribution of such cannibalism to egg mortality remains largely undocumented. Bogner and Eisner (1991) witnessed four instances of egg cannibalism among $137 \mathrm{U}$. ornatrix

\footnotetext{
${ }^{1}$ Paper no. 133 of the series Defense Mechanisms of Arthropods; No. 132 is Attygalle et al., Experientia (in press).

${ }^{2}$ Department of Zoology, Brandon University, Brandon, Manitoba, R7A 6A9, Canada.

${ }^{3}$ Section of Neurobiology and Behavior, Cornell University, Ithaca, New York, 14853.
}

Manuscript received 1 September 1995. 
egg clusters attached to $C$. mucronata in the field, indicating that such cannibalism does indeed occur at times in nature. Incidents of predation on these clusters, in many cases apparently by a chrysopid larva (Ceraeochrysa cubana), was substantially higher.

$U$. ornatrix larvae are apparently driven to cannibalism by a hunger for PA. They preferentially cannibalize eggs and pupae laden with PA over those devoid of PA, and are more prone to engage in cannibalism if they are themselves systemically deficient in PA (Bogner and Eisner, 1991, 1992). Unanswered was the question whether the larvae, in their cannibalistic choice, discriminate relatives from nonrelatives. Since eggs are clustered by females at oviposition, a cannibalistic larva might drastically reduce any component of indirect fitness by cannibalizing closely related siblings. Individuals may also compete more successfully for resources by cannibalizing nonkin. A mechanism via which kin could be discriminated from nonkin would thus confer a selective advantage upon individuals expressing that ability. We here present evidence that kin discrimination is not manifested in the context of egg cannibalism.

Our experiments consisted of presenting young larvae with a choice of eggs stemming respectively from their own parents and from another parental set, and determining whether they preferentially cannibalized one egg type over the other.

\section{Materials ANd Methods}

The eggs of $U$. ornatrix receive PA both from the mother and from the spermatophores the mother obtains from her mates (Dussourd et al., 1988). Females lay their eggs on Crotalaria leaves in dense clusters, comprising from few to 100 eggs/cluster $[\bar{x}=20.2$ \pm 2.3 (SE); $\mathrm{n}=45$ clusters] (Bogner and Eisner, 1991).

The $U$. ornatrix used in the present study stemmed from a laboratory culture, established from individuals taken near Lake Placid, Highlands County, Florida. We routinely raise moths in this culture to be either PA-containing (reared on a diet containing Crotalaria seeds), or PA-free (reared on a diet based on pinto beans, lacking Crotalaria seeds) (Bogner and Eisner, 1991). Larvae and eggs used in the present tests were derived from crossings of PA-free females and PA-containing males. This insured that the larvae were relatively PA-impoverished and therefore avidly cannibalistic (having 
received PA from the male parent only), and the eggs sufficiently PA-enriched to be cannibalistically attractive to the larvae (eggs entirely devoid of PA are virtually ignored by larvae) (Bogner and Eisner, 1991).

Thirty pairs of females (virgin, PA-free) and males, (virgin, PAcontaining) were set up separately in mating chambers $(0.351$ cylindrical cardboard containers) on 19 February, 1993. The chambers were lined with multiple layers of wax paper, allowing eggs to be harvested daily by removal of the innermost paper lining. Eggs first appeared on 24 February in 11 of the 20 chambers and were transferred (still attached to their paper backing) to separate plastic culture dishes, labeled to denote date of deposition and parental provenance of eggs. Eggs laid on any one day hatched in close synchrony, within five days $[\bar{x}=4.1 \pm 0.1$ (SD), $n=11$ clusters] of deposition ${ }^{1}$. Larvae used for testing were single individuals selected (by arbitrary choice) from among such clustermates, at age of two days (during which they had been kept unfed). These larvae were transferred individually to the center of culture dishes (14 cm diameter, $2.5 \mathrm{~cm}$ deep), where each was offered two egg clusters oviposited during the previous $24 \mathrm{hr}$, respectively by their own parents and by another parental pair. Although the initial number of eggs upon oviposition varied considerably, all clusters presented in the tests were standardized so as to consist of 10 eggs affixed to (approximately) $3.5 \mathrm{~cm}^{2}$ of paper backing. The two clusters were introduced in opposite quadrants of the dish, at about 2.5 $\mathrm{cm}$ from dish center [to permit identification of the clusters, one (designated by coin toss) was demarked by a small incision on the paper edge].

The preceding procedure was repeated with 1 to 4 larvae per each of the 11 sets of parents that yielded eggs, for a total of 27 replicate tests (27 February to 6 March). Where larvae of common parentage were used, these always received their nonparental eggs

\footnotetext{
${ }^{1}$ Emergence times of individual clustermate larvae deviate from the mean emergence time for the cluster by a standard error ranging from 6.7 to $33.0 \mathrm{~min}[\overline{\mathrm{X}}=$ $17.1 \pm 1.6$ (SE) min; $n=16$ clusters ranging in size from 10 to 32 eggs] (Maria Eisner, unpublished data to be presented in detail as part of a separate study). Newly emerged larvae all consume their own egg shells. They only rarely, upon emergence, attack clustermate eggs that are slower to hatch, although they usually remain with the cluster until all eggs have hatched.
} 
from different sources, thus insuring that such replicates could be regarded as independent.

Test dishes were set up in the dark at $23 \pm 2{ }^{\circ} \mathrm{C}$. At intervals of 24,48 , and $72 \mathrm{hr}$ following introduction of the eggs, each dish was checked for incidence of cannibalism, and scored as the fraction of eggs per cluster that bore evidence of larval attack (distinct perforation of egg shell, coupled with partial or total disappearance of egg contents). Because larvae were offered parental and nonparental eggs simultaneously, and the distribution of differences in the number of eggs of the two types cannibalized did not depart significantly from normality at any time interval (D'Agostino's Dtest, all $P>0.05$ ), a paired-sample t-test was used to examine whether any differences in the number of parental and nonparental eggs cannibalized occurred at each time interval. As a further test for preferential cannibalism, the ratio of the number of larvae that cannibalized a greater number of nonparental eggs to that of larvae that cannibalized a greater number of parental eggs after $72 \mathrm{hr}$ was compared to a 1:1 ratio (expected where no preference exists) using a $\mathrm{G}$ test.

\section{RESULTS}

The difference in number of own versus other parents' eggs cannibalized was not statistically significant at any time interval sample $\left(24 \mathrm{hr}, \underline{\mathrm{t}}_{26}=-1.17, P=0.25 ; 48 \mathrm{hr}, \underline{\mathrm{t}}_{26}=-0.50, P=0.62 ; 72\right.$ $\left.\mathrm{hr}, \underline{\mathrm{t}}_{26}=-1.10, P=0.28\right)$. In general, egg cannibalism increased over time, and although the mean number of nonparental eggs cannibalized slightly exceeded that of parental eggs cannibalized throughout (Fig. 1), the ratio of larvae that cannibalized more nonparental eggs to those that cannibalized more parental eggs $(3: 2)$ did not differ significantly from $1: 1\left(\mathrm{G}_{\mathrm{w}, 1}=0.79, P=0.38\right)$. Of the 27 larvae, 8 cannibalized more of their own parents' eggs, 12 cannibalized more of the other parents' eggs, and 7 cannibalized equal numbers of parental and nonparental eggs, after $72 \mathrm{hr}$.

\section{DISCUSSION}

Kin discrimination vis à vis eggs evidently did not occur in the context of our cannibalism experiments with larval $U$. ornatrix. If one considers the life history of $U$. ornatrix, it is apparent that the 
moth is not subject to the sort of selective pressure that would force the evolution of a mechanism for discrimination of related from unrelated eggs on the part of larvae. First and foremost, the development and hatching of $U$. ornatrix eggs within clusters is essentially synchronous. That synchrony could itself be viewed as protective against cannibalism. Over evolutionary time, a larval propensity to feed on eggs upon emergence would have exerted a strong stabilizing force on intracluster rates of development. We also view it as significant that $U$. ornatrix larvae do not apparently engage in egg cannibalism immediately upon hatching. Further, egg clusters in the field tend to be widely dispersed. One only rarely finds clusters on closely adjacent leaves, even at times when $U$. ornatrix populations are dense (T. Eisner, unpublished observations on Crotalaria mucronata in Florida). There is therefore a low probability of larvae coming upon nonclustermate kin eggs, and little cost (to inclusive fitness) to their cannibalizing whatever eggs

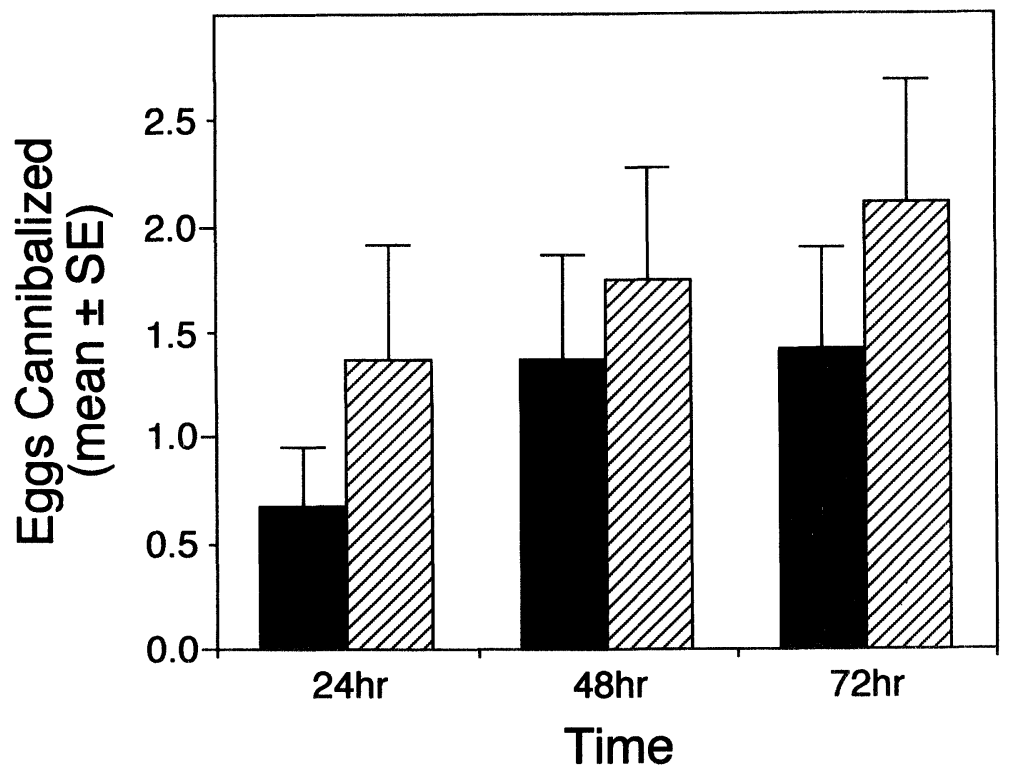

Fig. 1: Mean number of parental eggs (solid bars) and nonparental eggs (crosshatched bars) cannibalized by single Utetheisa ornatrix larvae $(n=27)$ after 24,48 , and $72 \mathrm{hr}$. 
they do encounter. Indeed, indiscriminate egg cannibalism could be advantageous to larvae, in the context of resource competition with unrelated individuals. However, the cannibalism of even related eggs could be viewed as advantageous, if by consuming such eggs a larva remedies a systemic PA deficiency (i.e., resource exploitation, sensu Hausfater and Hrdy, 1984). In such cases the benefit derived from PA acquisition could outweigh the cost incurred to inclusive fitness.

Despite the absence of kin-differential cannibalism in the present study, the possibility remains that larvae hatching in the natural context manifest kin discrimination abilities. The coefficient of relatedness among clusters employed in our tests may have become inflated through inbreeding in the laboratory culture. Thus eggs may not have differed sufficiently in any innate cues that would normally promote discrimination. Similarly, laboratory-reared moths may experience an artificially homogeneous diet, which would preclude the contribution of any environmentally derived and thus potentially parent-specific discriminator substances underlying the discrimination process. Finally, kin discrimination may occur in the natural setting without kin recognition proper (sensu Grafen, 1990). Numerous animals rely on spatial cues to discriminate kin from nonkin, treating individuals found in the natal area as relatives and those remote to the natal area as nonrelatives (see Fletcher and Michener, 1987; Hepper, 1991 for reviews). Where any asynchrony in hatching occurs in the field, larvae could avoid the cannibalism of close kin by avoiding neighboring eggs.

The resolution of these issues awaits data garnered in a fieldsetting, though our results prompt the prediction that any of these mechanisms allowing the discrimination of kin from nonkin are unnecessary. The considerable synchrony in hatching within clusters, the dispersion of clusters among plants in nature, and indeed the fact that $U$. ornatrix hatch into a world where both food and PA are readily available from the host plant render the evolution of a discrimination mechanism unlikely.

\section{ACKNOWLEDGMENTS}

This study was supported by a Natural Sciences and Engineering Research Council of Canada post-doctoral fellowship to JFH, 
and National Institutes of Health grant AI02908 to TE. We thank Ken Amerman for culturing the moths, Curtis Blankespoor, Craig LaMunyon, and Scott Smedley for helpful discussions, two anonymous reviewers for comments on the initial manuscript, and Janis Strope for numerous kindnesses.

\section{Literature Cited}

Bogner, F. and T. Eisner. 1991. Chemical basis of egg cannibalism in a caterpillar (Utetheisa ornatrix). J. Chem. Ecol. 17:2063-2075.

Bogner, F. and T. Eisner. 1992. Chemical basis of pupal cannibalism in a caterpillar (Utetheisa ornatrix). Experientia 48:97-102.

Dussourd, D. E., K. Ubik, C. Harvis, J. Resch, J. Meinwald, and T. Eisner. 1988. Biparental defensive endowment of eggs with acquired plant alkaloid in the moth Utetheisa ornatrix. Proc. Natl. Acad. Sci. USA 85:5992-5996.

Eisner, T. and M. Eisner. 1991. Unpalatability of the pyrrolizidine alkaloid-containing moth; Utetheisa ornatrix, and its larva, to wolf spiders. Psyche 98:111-118.

Eisner, T. and J. Meinwald. 1987. Alkaloid-derived pheromones and sexual selection in Lepidoptera, pp. 251-269 In G. D. Prestwich and G. J. Blomquist [eds.]. Pheromone Biochemistry. Academic Press, Orlando, Florida. 565 pp.

Eisner, T. and J. Meinwald. 1995. The chemistry of sexual selection. Proc. Natl. Acad. Sci. USA. 92:50-55.

Fletcher D.J.C. and Michener C.D. (eds). 1987. Kin Recognition in Animals. Wiley-Interscience, New York: $465 \mathrm{pp}$.

Grafen, A. 1990. Do animals really recognize kin? Anim. Behav. 39:42-54.

Hare, J. F. and T. Eisner. 1993. Pyrrolizidine alkaloid deters ant predators of Utetheisa ornatrix eggs: effects of alkaloid concentration, oxidation state, and prior exposure of ants to alkaloid-laden prey. Oecologia 96:9-18.

Hausfater, F. and S.B. Hrdy. 1984. Infanticide: Comparative and Evolutionary Perspectives. Aldine Press, New York.

Hepper, P.G. (ed). 1991. Kin Recognition. Cambridge University Press, Cambridge: $457 \mathrm{pp}$. 

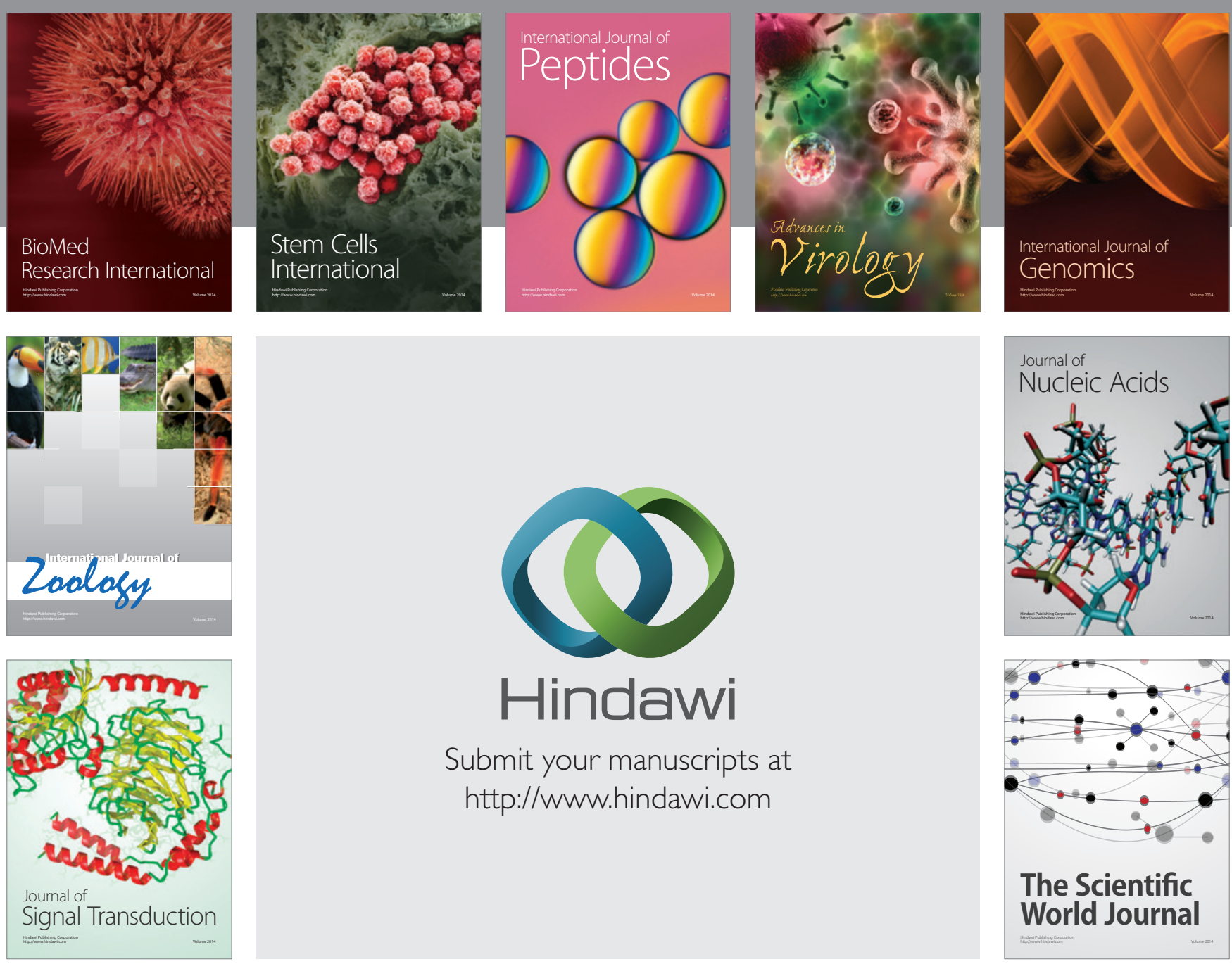

Submit your manuscripts at

http://www.hindawi.com
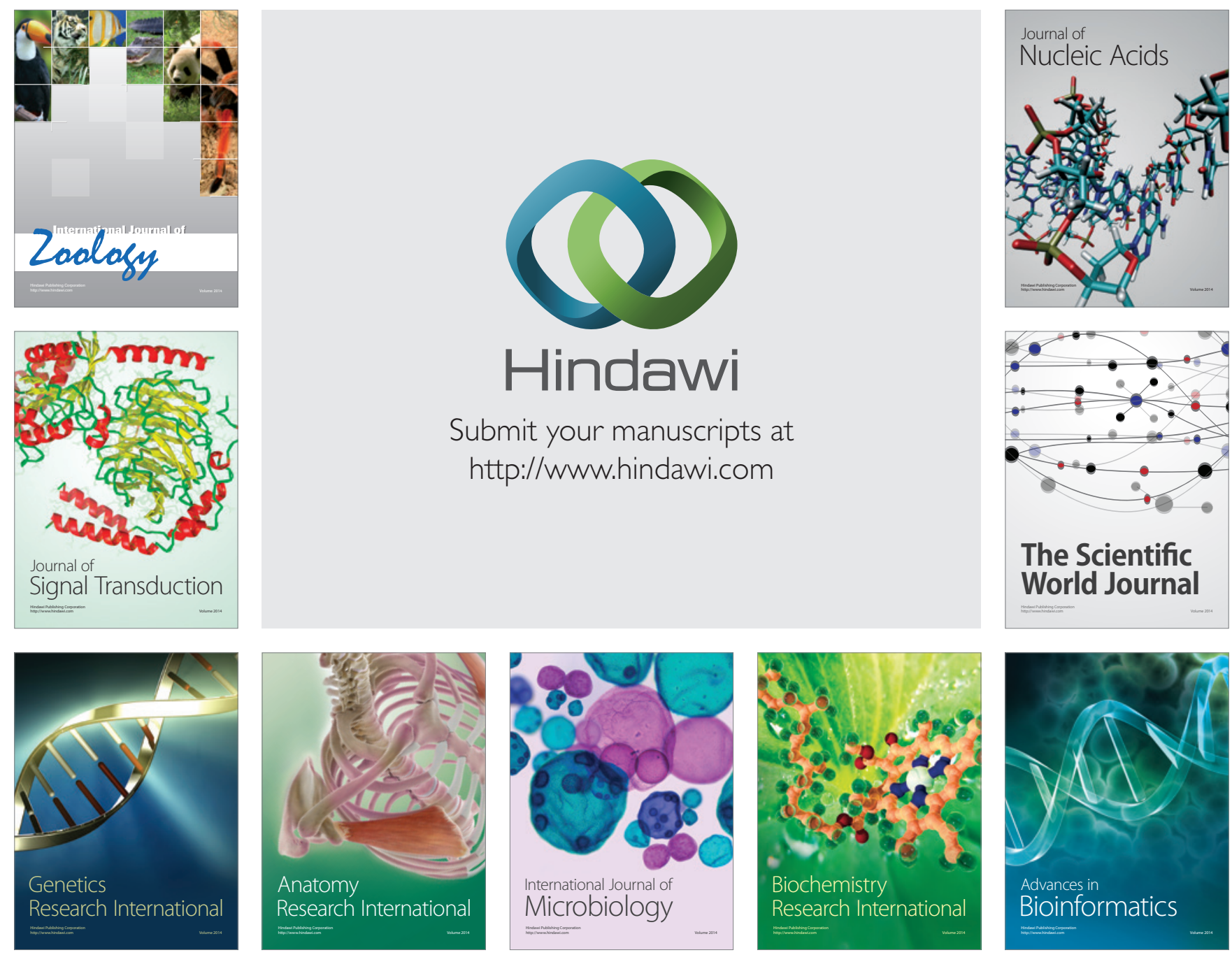

The Scientific World Journal
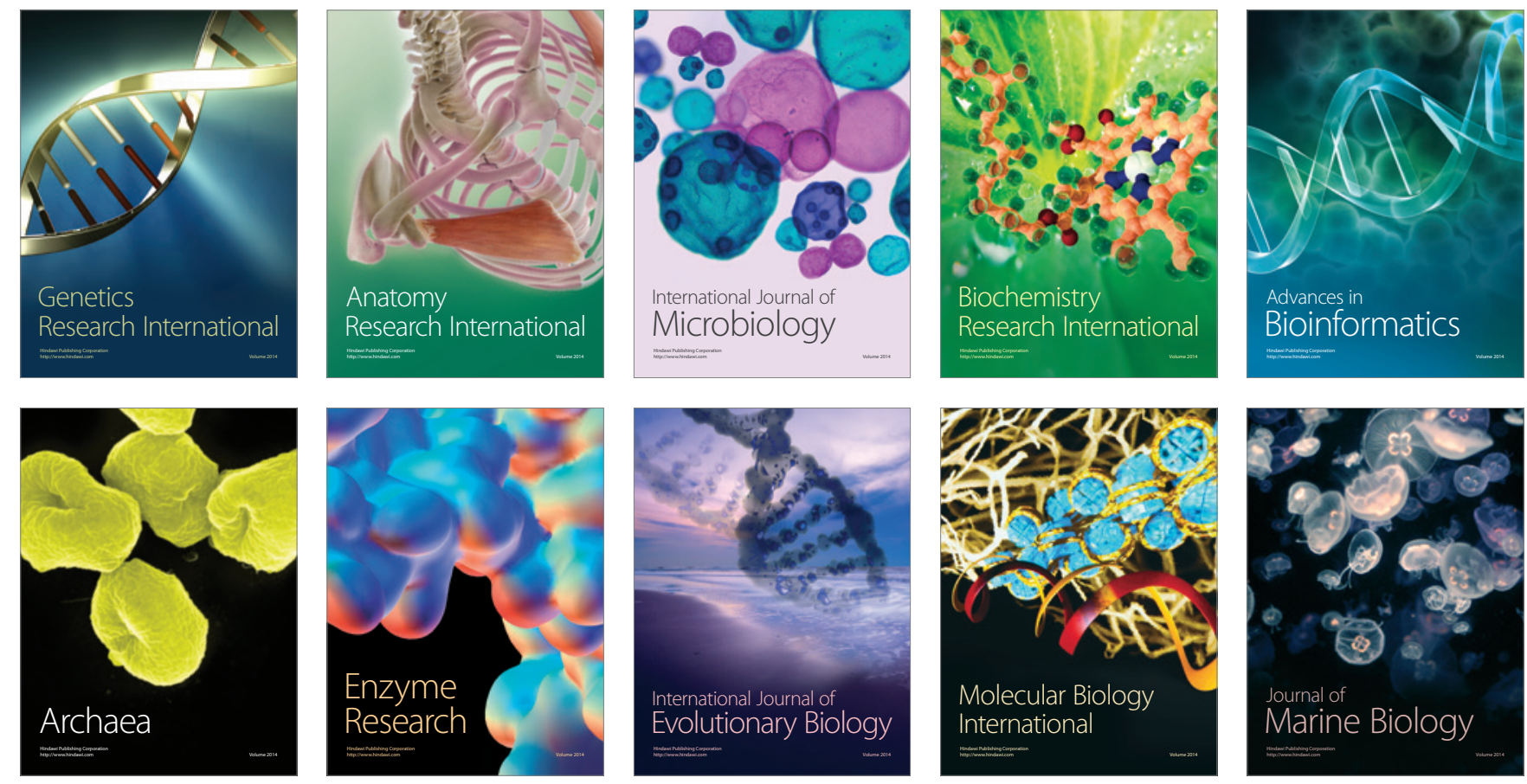